\title{
TEACHERS' PERCEPTIONS REGARDING THE USE OF INTERACTIVE WHITEBOARDS TO ENHANCE ELEMENTARY LITERACY DEVELOPMENT
}

\author{
Takashi Crum and John W. Hatcher III \\ New York City Department of Education, New York, New York 11201, USA \\ Southeastern Louisiana University SLU 10549, Hammond, LA. 70402, USA
}

\begin{abstract}
This research study explored the effective use of interactive whiteboards to prepare students with basic literacy concepts to compete in a global economy. A single case study was employed to explore elementary teachers' adoption rates of interactive whiteboards (IWBs) to improve elementary literacy development. This qualitative narrative approach used observations, interviews, member-checking, and field notes to explore elementary teachers' perceptions related to professional development training for literacy instruction. The findings of this study revealed themes of integrated technology, instruction, elementary teacher perceptions, and elementary teacher's self-efficacy about using interactive whiteboards to improve elementary literacy development.
\end{abstract}

\section{KEYWORDS}

Elementary Literacy, Integrated Technology, Interactive Whiteboards (IWBs)

\section{INTRODUCTION}

In the United States of America, the inability to read and utilize print materials was viewed as an individual problem with implications for career opportunities, educational attainment, self-fulfillment, and participation in society (Lu, Ottenbreit-Leftwich, Ding, \& Glazewski, 2017). According to the National Assessment of Adult Literacy, literacy was learned, while illiteracy was passed along from parents who could not read or write. The National Center for Education Statistics (2015) reported that one out of four children grow up not knowing how to read. Molin and Lantz-Andersson (2016) stated digital technologies for reading impacted what and how literacy instruction was provided to enhance student learning. Instructional resources such as digital technologies, interactive whiteboards (IWBs), and iPads were often used inefficiently; the literacy instruction students received rarely required them to read print. The National Assessment of Educational Progress (2011) reported that $33 \%$ of general education students and $68 \%$ of students with disabilities scored below the basic level on their grade level assignment. The efforts of the No Child Left Behind Act, prompted evidence-based literacy instruction in classrooms and transformed evidence-based literacy instruction into practical instructional standards that helped to develop the foundations of authentic learning in classroom environments (Sumak, Pusnik, Hericko, \& Sorgo, 2017).

\section{BODY OF PAPER}

Low literacy rates among elementary students in the United States have been a grave concern regarding readiness for the 21st century global economy. Since the late 1990s, governments and schools have increased their investment to provide an effective technology infrastructure around the assumption that student achievement and elementary teachers' instructional practices would be enhanced. In addition, technology would alter education such that teaching, and learning would be more effective (Kearney, Schuck, Aubusson, \& Burke, 2018). Given some elementary teachers' apprehension about technology integration, this study explored the low rates of elementary teachers' adoption of the interactive style technology to enhance 
elementary literacy development. The specific purpose and nature of this qualitative single case study was to explore elementary teachers' perceptions regarding the usage of interactive whiteboards in the classrooms of an inner-city school located in the Bronx, New York. The following questions guided the study:

- How do elementary teachers perceive the interactive whiteboard as a resource to improve literacy skills?

- How do elementary teachers perceive interactive whiteboards as a tool to enhance their teaching practices?

- How do elementary teachers perceive the interactive whiteboard as it relates to teachers' training and pre-literacy development in early elementary students?

The integration of the interactive whiteboard was grounded in the Technological Pedagogical and Content Knowledge framework (TPACK), which encompassed the complex nature of teaching and how the integration of technology compounded elementary teachers' ability to effectively teach (Koehler, Mishra, \& Cain, 2013). The TPACK was an extension of Shulman's (1986) Pedagogical Content Knowledge (PCK) framework and included knowledge of technology (See Figure 1.). Researchers described TPACK as a complex structure that delineated elementary teachers' interrelated knowledge of instructional standards related to content, pedagogy, and technology, while further reporting that educators gained the knowledge needed to integrate technology into their pedagogical practices effectively (Koehler, Mishra, \& Cain, 2013). Researchers conducted a cluster analysis using the TPACK framework and discovered how elementary teachers' TPACK development was used to teach technology, content knowledge, and pedagogy, which were required factors to effectively design, engage, and analyze curriculum and instruction with technology effectively (Koh \& Chai, 2014).

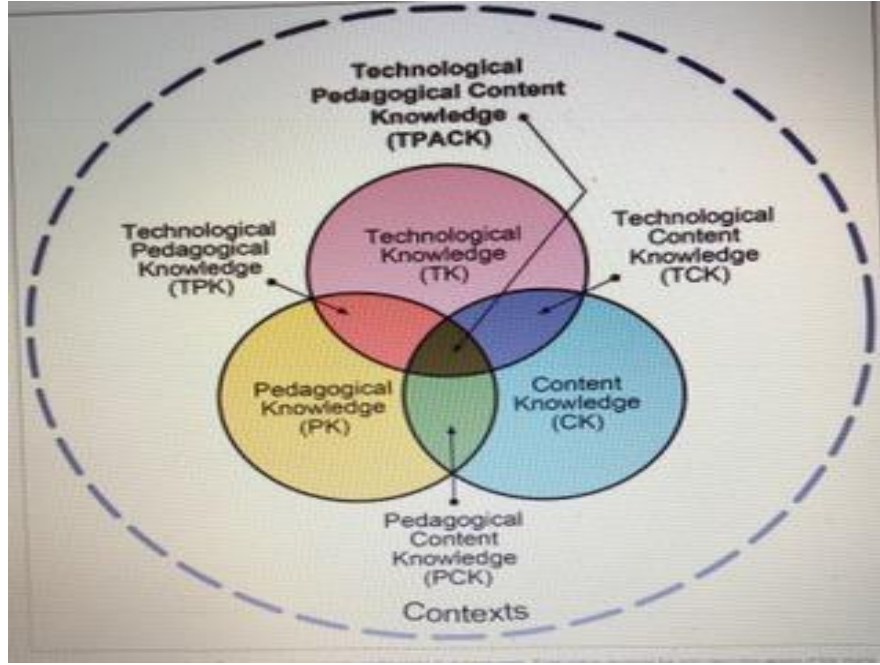

Figure 1. Three domains of elementary teachers' knowledge required to effectively teach and integrate technology Adapted from What is technological pedagogical content knowledge (TPACK)? by Koehler, M. J., Mishra, P., \& Cain, W. (2013). Journal of Education, 193(3), 13-19. Reproduced by permission of publisher, @ 2012 by tpack.org

\subsection{Literacy Proficiency}

In New York City public schools, there was a critical need for literacy education between 2009 and 2013. Approximately 26 percent of the student population could not speak English proficiently. Specifically, in the borough of the Bronx, $3 \%$ of the student population were not receiving literacy education (Zong \& Batalova, 2015). The ability to assess, evaluate, and integrate information from a wide range of textual sources defined what it meant to be literacy proficient (Clarke, 2014). Literacy proficiency requires students to decode known and unknown vocabulary, comprehend print and digital print materials, and strong phonemic awareness knowledge. Critical literacy skill for struggling readers was phonological awareness which is an essential factor for reading instruction, fluency, and comprehension (Alhumsi \& Affendi, 2014). Technology was redefining reading success for student literacy skills necessary to align with the changing model (Hutchison \& Beschorner, 2015). 


\subsection{Technology Integration}

Technology usage enhanced the efficiency of delivering content knowledge and it extended beyond the classroom environment yet, it did not explore interactive whiteboard technology's direct role in enhancing literacy learning and instruction. Keane, Keane, and Blicblau (2016) explored the issue regarding the gap between technology usage and academic achievement; the findings provided statistics that reflected how appropriate technology usage affects students' educational achievements. The integration of the IWBs opened a virtual environment to deliver and support learning activities within a group who were connected by common characteristics such as identity features, values, beliefs, interests, and goals (Farjon, Smits, \& Voogt, 2019). However, according to Thoma, et. al. (2017), technology integration occurred infrequently or superficially in some classrooms and literacy instruction was dependent on technology integration to provide active learning and established a developmentally appropriate environment for problem-solving, supporting individual learning, and assessment and progress in students' learning. While the integration of the interactive whiteboard helped build a more visual and interactive learning environment conducive to teaching; elementary teachers' high involvement was related to significant student outcomes, but the actual role interactive whiteboard usage played in literacy achievement and instruction was not explored (McKnight, O’Malley, Ruzic, Horsley, Franey, \& Bassett, 2016).

\subsection{Elementary Teachers' Perception}

Karaseva, Siibak, and Pruulmann-Vengerfeldt (2015) discovered that many people believe that technology played an integral part in student learning, but some elementary teachers believed otherwise. Transforming the learning environment relied on elementary teachers' perceptions, training, and selection of developmentally appropriate curriculum, software, and applications. The findings suggested that elementary teachers' redesign of technology integrated activities enhanced student learning and elementary teachers' experience of introducing technology, specifically interactive whiteboard technology for organization, professional development, and student achievement was identified (Karaseva, et al., 2015). Elementary teachers improved their teaching practice by accessing cutting edge learning resources and materials, adopted a student-centered approach to instruction, and enhanced communication between elementary teachers, students, and parents (Langub \& Lokey-Vega, 2017).

\section{METHODOLOGY}

In this study, the researcher employed a single school narrative case study to describe elementary teachers' perceptions of the use of the interactive whiteboard as a tool to enhance the teaching and learning of elementary literacy skills. This qualitative methodology was appropriately designed to provide an interpretive analysis of elementary teachers' perspectives that gave voice to their lived experiences (Yin, 2016). A purposeful sample size was utilized of elementary teachers from kindergarten through 2nd grade at an inner-city public school in New York City. The goal of this study was to present the value of the interactive whiteboard for student learning and elementary teachers' perceptions related to professional development for literacy instruction. The New York City school district comprised 1,722 schools across five boroughs during this study. The participating school in this study was one of 98 schools in district 9 of the Bronx, New York. This inner-city elementary school educates students in grades Pre-K through fifth grade. The targeted population included elementary teachers with three or more years of teaching experience. The sample of participants in this study demonstrated four specific characteristics, (1) they were certified elementary teachers, (2) they had more than three years of teaching experience, (3) they taught grades kindergarten thru 2nd, and (4) they used technology in the classroom for at least one year. The sampling pool of participants consisted of 25 elementary teachers; 15 elementary teachers were general educators, five were intervention specialists, and five were special educators. A sample of 12 elementary teacher participants who met the criteria were sought to provide an adequate voice for elementary teachers' perceptions regarding the integration of IWBs as a tool to enhance literacy development. 
The researcher was the primary instrument for data collection within a prescribed method for engaging participants, organizing data, and facilitating interviews. There were six sources of evidence and three principles of data collection for conducting this case study: direct observation, participant observation, documentation, archival records, interviews, and physical artifacts. The three principles of data collection used by the researcher were (a) use of multiple sources of data, (b) the creation of a case study database, and (c) the maintenance of a chain of evidence (Yin, 2016). Data were collected using a semi-structured interview protocol followed by 45-minute classroom observations. The interviews were bound by a field-tested interview protocol. The interview protocol was used to gather in-depth knowledge about elementary teachers' perceptions regarding the challenges they faced utilizing the interactive whiteboard to enhance literacy skills. To fortify credibility and transferability, data sources were triangulated using data collected during observation and coded on the observational guide to highlight how elementary teachers adopted the use of IWBs during literacy lessons, identified themes related to the research question(s), and denoted any occurrences related to elementary teachers' training. The 12 interviews were conducted in individual elementary teachers' classrooms afterschool at least one week before the classroom observations. A semi-structured interview protocol was used to ask questions and each interview was recorded using a digital recorder such as an iPad or iPhone. Data from each interview and field notes were processed by using unidentifiable code to protect participants' privacy. The data analysis was done manually. The conclusion of interview transcription, data analysis was printed out on a spreadsheet. The spreadsheet contained three columns pertaining to participants' identification number, the question, and the response. A basic content analysis methodology was applied to categorize the data and member checking occurred to validate the data (Saldana, 2015). Limitations of the study were relying on self-reported data as the main method of data collection and the population of teachers participating was small and consisted of 12 teachers; although attempts were made to include participants that were in many ways representative of the single school case. The themes derived from participant interviews and the classroom observations were grouped and discussed according to the research questions and applied to the following subsections: pedagogical beliefs, value beliefs, training, and support, and IWB usage for literacy instruction.

\section{DISCUSSION}

In this qualitative single case study approach, the questions were developed to gain insight relating to elementary teachers' perceptions of the interactive whiteboard as a tool for not only improving elementary teachers' pedagogy but reading literacy among their students. The findings of this study revealed themes of integrated technology, instruction, elementary teachers' perceptions, and elementary teachers' self-efficacy about using interactive whiteboards to improve elementary literacy development.

All participants agreed that integrating IWBs provided both whole class and small group interactive experience for visual, auditory, and kinesthetic learners. Thus, the instructional process unfolded gradually with elementary teachers' explicit instruction, guided practice, partner practice, and then independent practice. "I create and write lessons, ELA specifically to teach phonemic awareness and decoding strategies as it presents students the opportunity to not only learn but be engaged and practice independently." Three participants stated that interactive whiteboards allowed them the opportunity to explore various teaching strategies and methods. "IWB is essential because it provides another teaching voice to clarify students" misconceptions and reinforces a more engaging way for students to memorize taught concepts.” Despite elementary teachers' comfort level, some elementary teachers readily incorporated IWBs for not only literacy instruction but all subjects to customize the instructional needs of students. "I utilize it to display the information that you need students to learn, i.e., interactive websites, games, and just presenting/displaying the information whereas students can hear, see, and interact with the information." However, elementary teachers' overall perceptions regarding the interactive whiteboard as it related to elementary teacher training and pre-literacy development in early elementary students were mixed.

Elementary teachers' lack of training rendered IWBs usage ineffective for pre-literacy development because the IWBs usage was limited to engagement and motivation for students but not teaching and learning. "Since technology is readily available, students have at home access thus their learning was not affected." Yet, "my lack of confidence and experience renders IWBs usage ineffective." Some elementary teachers also believed that training or professional development should be consistently offered throughout the school year to effectively teach and enhance student learning in all subjects; consistency would build confidence in IWBs 
usage. "I believe usage and impact would be more effective if training was consistent; inconsistent access and dilapidated machinery are a hindrance to IWBs usage and integration." Since elementary teachers were solely in control in their classrooms, their voices for training, support, and respect for their knowledge regarding teaching and learning were imperative to preparing $21^{\text {st }}$-century global citizens and eradicating low literacy rates.

It was discovered that elementary teachers' beliefs had the maximum impact on technology usage because elementary teachers controlled the presented content, the method of presentation, students' interaction, and the tools and resources needed for student learning. "I believe IWBs are a valuable tool that have a high impact on teaching and learning; my students are highly motivated to learn, more attentive and focused and instruction is student-centered and self-directed." Overall, participants stated interactive whiteboard technology provided a motivational tool for students to be actively engaged learners, changed how participants thought about planning lessons, how to teach certain learning objectives, and provided another resource for lessons to be student-centered rather than teacher directed. This knowledge aligned with the theoretical framework, TPACK which provided the instructional standards educators needed and used to effectively plan and teach with technology, which impacted literacy instruction and learning.

\section{CONCLUSION}

The integration of technology into schools and classrooms in the 21st century has enhanced the teaching and learning process for both educators and students regarding elementary literacy development. This technological revolution was the introduction of the interactive whiteboards, which became a critical resource to enhance how elementary teachers taught and engaged their students to enhance elementary literacy skills. The perceptions of elementary teachers in this study found that the use of interactive whiteboards empowered students to take greater responsibility for the development of their learning and the use of interactive whiteboards was a critical tool to enhance elementary teachers' instructional delivery. Finally, the elementary teachers in this study perceived that when professional development was consistent and designed specifically to increase their self-efficacy with the use of interactive whiteboards value was added to their pedagogy. The relevant knowledge derived from this study may encourage other elementary teachers to embrace the difficult task of infusing technology into their elementary literacy lessons to improve students' literacy development. This study's findings offered insight for educators to overcome low literacy rates among early elementary students by recognizing the underutilization of the interactive whiteboard as a tool to improve students' literacy and other basic skills. The increase in the use of technology in the teaching and learning process is hopefully heading in a positive direction especially after the COVID-19 pandemic.

\section{ACKNOWLEDGEMENT}

We thank the New York City Department of Education and the administrative team for their consent to engage in this study. In addition, we acknowledge the single elementary school in the borough of the Bronx and our deepest gratitude for all the elementary teachers who provided their time, classrooms, professional perspective, their lived experiences regarding technology integration, and the benefits and limitations of the interactive whiteboard as a tool to enhance student achievement. We are also grateful to Koehler, M.J., Mishra, P., \& Cain, W. (2013) for granting permission to use their TPACK framework.

\section{REFERENCES}

Alhumsi, M. H. \& Affendi, A. (2014). Beginning readers have no prior experience with sound segmentation. Journal of Education and Practice, 5(11), 32-41. Retrieved from www.iiste.org

Cakiroglu, O. (2015). Elementary teachers' views on the use of interactive whiteboards in secondary schools. Eurasia Journal of Mathematics, Science \& Technology Education, 11(2), 251-259. Retrieved from www.ejmste.com

Clarke, L.W. (2014). Reader response 2.0: Using technology to support literacy growth. New England Reading Association Journal, 50(1), 44-49. Retrieved from http://www.nereading.org 
Farjon, D., Smits, A., \& Voogt, J. (2019). Technology integration of pre-service elementary teachers explained by attitudes and beliefs, competency, access, and experience. Computers \& Education, 130, 81-93. doi: 10.1016/j.compedu.2018.11.010

Hutchison, A. \& Beschorner, B. (2015). Using the iPad as a tool to support literacy instruction. Technology, Pedagogy and Education, 24(4), 1-16. doi: 10.1080/1475939X.2014.918561

Karaseva, A., Siibak, A., \& Pruulmann-Vengerfeldt, P. (2015). Relationships between elementary teachers' pedagogical beliefs, subject cultures, and mediation practices of students' use of digital technology. Cyberpsychology: Journal of Psychosocial Research on Cyberspace, 9(1). doi: 10.5817/CP.2015.1.6

Keane, T., Keane, W.F., \& Blicblau, A.S. (2016). Beyond traditional literacy: learning and transformative practices using ICT. Education and Information Technologies, 21(4), 769-781. doi: 10.1007/s10639-014-9353-5

Kearney, D., Schuck, S., Aubusson, P., \& Burke, P. (2018). Elementary teachers' technology adoption and practices: Lessons learned from the IWB phenomenon. Elementary Teacher Development, 22(4), 481-496. doi: 10.1080/13664530.2017.1363083

Koehler, M. J., Mishra, P., \& Cain, W. (2013). What is technological pedagogical content knowledge (TPACK)? Journal of Education, 193(3), 13-19. doi:10.1007/978-1-4614-3185-5_9

Koh, J.H.L. \& Chai, C.S. (2014). Elementary teacher clusters and their perceptions of technological pedagogical content knowledge TPACK) development through ICT lesson design. Computers \& Education, 70, 222-232. doi: 0.1016/j.compedu.2013.08.017

Langub. L. \& Lokey-Vega, A. (2017). Rethinking instructional technology to improve pedagogy for digital literacy: A design case in a graduate early childhood education course. Tech Trends, 61(4), 322-330. doi: 10.1007/s11528-0170185-1

Lu, Y., Ottenbreit-Leftwich, A.T., Ding, A., \& Glazewski, K. (2017). Experienced iPad-using early childhood elementary teachers: Practices in the one-to-one iPad classroom. Computers in the Schools, 34(1-2), 9-23. doi: 10.1080/07380569.2017.1287543

McKnight, K., O’Malley, K., Ruzic, R., Horsley, M.K., Franey, J.J., \& Bassett, K. (2016). Teaching in a digital age: How educators use technology to improve student learning. Journal of Research on Technology in Education, 48(3), 194-211. doi: 10.1080/15391523.2016.1175856

Molin, L. \& Lantz-Andersson, A. (2016). Significant structuring resources in the reading practices of a digital classroom. Journal of Information Technology Education: Research, 15, 131-156. Retrieved from http://www.informingscience.org/Publications/3513

National Assessment of Educational Progress (NAEP). (2011). Nation's Report Card: Reading (NCES 2012-457). Washington, D.C.: U.S. Government Printing Office.

National Center for Educational Statistics (NCES). (2015). The Condition of Education 2015. (NCES 2015-144). Washington, D.C.: U.S. Government Printing Office.

Saldana, J. (2015). The coding manual for qualitative researchers. Thousand Oaks, CA: Sage Publications.

Sumak, B., Pusnik, M., Hericko, M., \& Sorgo, A. (2017). Differences between prospective, existing, and former users of interactive whiteboards on external factors affecting their adoption, usage, and abandonment. Computers in Human Behavior, 72, 733-756. doi: 10.1016/j.chb.2016.09.006

Thoma, J., Hutchison, A., Johnson, D., Johnson, K., \& Stromer, E. (2017). Planning for technology integration in a professional learning community. The Reading elementary teacher, 71(2), 167-175. doi: 10.1002/trtr.1604

Yin, R.K. (2016). Qualitative research from start to finish. New York, NY: The Guildford Press.

Zong, J. \& Batalova, J. (2015). European Immigrants in the United States. Migration Policy Institute. Retrieved from www.migrationpolicy.org 